О.О. МЕЛЬНИЧЕНКО ${ }^{1}$, О.Р. БАБАЕВ ${ }^{1}$, К.М.Н., В.В. ШАХЗАДОВ ${ }^{1}$, З.А. НЕВОЗИНСКАЯ ${ }^{1}$, К.М.Н., И.М. КОРСУНСКАЯ ${ }^{2}$, Д.М.Н., ПрОфеССОр

1 Московский научно-практический центр дерматовенерологии и косметологии Департамента здравоохранения г. Москвы

2 Центр теоретических проблем физико-химической фармакологии Российской академии наук, Москва

\title{
ПАПИЛЛОМАВИРУСНАЯ ИНФЕКЦИЯ.
}

\section{КАК ИЗБЕЖАТЬ РЕЦИДИВОВ?}

\begin{abstract}
В работе приводятся данные о распространенности ПВИ, частоте рецидивирования данной инфекции. Рассмотрены различные схемы терапии заболевания, включающие применение деструктивных методов терапии и сочетания их с иммуномодулирующей терапией. Приводятся данные собственных наблюдений.
\end{abstract}

Ключевые слова: папилломавирусная инфекция, вирус папилломы человека, инозин пранобекс, противорецидивная терапия.

O.O.MELNICHENKO ${ }^{1}$, O.R.BABAEV ${ }^{1}$, PhD in medicine, V.V.SHAKHZADOV ${ }^{1}$, Z.A.NEVOZINSKAYA ${ }^{1}$, PhD in medicine, I.M. KORSUNSKAYA2, MD, Prof.

${ }^{1}$ Moscow Scientific and Practical Center of Dermatology, Venereology and Cosmetology of Moscow City Health Department,

${ }^{2}$ Center for Theoretical Problems of Physicochemical Pharmacology, Russian Academy of Sciences, Moscow

PAPILLOMAVIRUS INFECTION. HOW TO AVOID RELAPS?

The paper presents data on the prevalence of PVI, the recurrence rate of this infection. It discusses various therapy protocols of the disease including the use of destructive methods in the treatment and combination of the above methods with immunomodulating therapy. The own observation data are provided.

Keywords: papillomavirus infection, human papillomavirus, inosine pranobex, anti-relapsing therapy.

апилломавирусная инфекция (ПВИ) является одним из самых распространенных заболеваний, поражающих аногенитальную область, а встречаемость остроконечных кондилом (проявление ПВИ) составляет приблизительно 19\% [1]. Также инфицированность урогенитального тракта вирусом папилломы человека (ВПЧ) среди лиц молодого и среднего возраста в некоторых популяциях достигает 34,4-44,9\% [2, 3]. По различным литературным данным, в мире ежегодно регистрируется от 2,5 до 3 млн случаев новых заражений ПВИ [4]. ВПЧ встречается в 3 раза чаще, чем генитальный герпес [5]. Считается, что к 50 годам 80\% женщин инфицированы ВПЧ [6]. В ходе некоторых исследований различные типы ВПЧ были выявлены в 99,7\% биоптатов, взятых у больных раком шейки матки по всему миру, что дает основание считать, что инфицирование женщин ВПч является важнейшим фактором канцерогенеза шейки матки [7, 8]. Существующие схемы терапии пациентов с различными проявлениями ПВИ направлены либо на деструкцию папилломатозных очагов, возникающих на месте внедрения вируса, либо на стимуляцию противовирусного иммунного ответа, либо на сочетание этих подходов [9]. Количество рецидивов колеблется и в среднем составляет 25-30\% в течение 3 месяцев после лечения [10]. Рецидивы аногенитальных бородавок чаще всего связаны с реактивацией инфекции, а не с реинфекцией от полового партнера.

Терапия пациентов с рецидивирующими остроконечными кондиломами представляет для врача наиболее сложную задачу, поскольку в подобных случаях неоднократное применение деструктивных методов лечения не дает положительной динамики. Даже после многократных курсов лечения рецидивирование прекращается лишь у 40\% больных [10]. Патогенез вирусных инфекций - иммунозависимый; их клиническая манифестация обычно связана с дефектами различных звеньев иммуни- тета. Важнейшей причиной клинической манифестации ПВИ и ее рецидивов являются нарушения в иммунной системе [11]. Комбинированное лечение таких больных, сочетающее иммуномодулирующую и деструктивную терапию, намного эффективней.

В Европейском руководстве по лечению дерматологических нозологий инозин пранобекс входит в список рекомендованных препаратов для терапии остроконечных кондилом и бородавок. В российских рекомендациях по ведению больных с инфекциями, передаваемыми половым путем, он также присутствует [12].

\section{Считается, что к 50 годам 80\% женщин} инфицированы ВПЧ [6]. В ходе некоторых исследований различные типы ВПЧ были выявлены в 99,7\% биоптатов, взятых у больных раком шейки матки по всему миру, что дает основание считать, что инфицирование женщин ВПЧ является важнейшим фактором канцерогенеза шейки матки

Инозин пранобекс - иммуномодулятор, стимулирующий противовирусную защиту организма. Препарат нормализует дефицит или дисфункцию клеточного иммунитета, индуцируя созревание и дифференцирование Т-лимфоцитов и Т1-хелперов, потенцируя индукцию лимфопролиферативного ответа в митогенных или антигенактивных клетках. Инозин пранобекс моделирует цитотоксичность Т-лимфоцитов и натуральных киллеров, функцию Т8-супрессоров и Т4-хелперов, а также повышает количество иммуноглобулина $\mathrm{G}$ и поверхностных маркеров комплемента. Препарат повышает синтез интерлейкина-1 (ИЛ-1) и ИЛ-2, регулирует экспрессию рецепторов ИЛ-2, существенно увеличивает секрецию эндогенного ү-интерферона и уменьшает продукцию 
ИЛ-4 в организме. Он усиливает действие нейтрофильных гранулоцитов, хемотаксис и фагоцитоз моноцитов и макрофагов. Инозин пранобекс также напрямую угнетает синтез вирусов путем встраивания инозина и оротовой кислоты в полирибосомы пораженной вирусом клетки, нарушая присоединение адениловой кислоты к вирусной РНК и, таким образом, обладает непосредственно противовирусным действием [13-15]. Одним из показаний к применению препарата является ПВИ гениталий у мужчин и женщин.

В инструкции по применению указано, что при рецидивирующей ПВИ дозировка инозина пранобекса составляет 3 г/сут (2 таблетки 3 р/сут) как дополнение к местной терапии или деструктивным методам лечения в течение 14-28 дней, далее с 3-кратным повторением указанного курса с интервалом в 1 мес.

Зарубежный опыт применения препарата по 1 г 3 p/ сут в течение 28 дней демонстрирует следующие результаты: количество рецидивов снижалось с 41\% после криодеструкции до 6\% при использовании комбинации инозина пранобекса и подофиллотоксина [16]. Схожие результаты при включении инозина пранобекса в терапию получены Г.Э. Баграмовой и соавт., количество рецидивов снизилось с 43,4\% при деструкционной терапии до 17,4\% при сочетании деструкций с инозином пранобексом [17].

Стоит отметить, что одним из показателей результативности терапии рецидивирующей ПВИ является исчезновение генома ВПЧ из очагов поражения. По некоторым данным, при применении инозина пранобекса этого показателя можно достичь в 98\% случаев [18]. Отмечают, что степень элиминации вируса зависит от длительности курса терапии. Исследования показывают исчезновение вируса в 66\% случаев после одного 10-дневного курса лечения, проведение второго такого курса повышало степень элиминации до 98\%. Полученные данные заставили продолжить изучение влияния длительности курса инозина пранобекса на результаты лечения. В качестве объекта исследования были взяты пациенты с начальны- ми поражениями шейки матки (ASCUS или LSIL), ассоциированными с ВПЧ высокого онкогенного риска, при этом сравнивали результаты 14- и 28-дневных курсов применения инозина пранобекса [19]. Полученные результаты демонстрируют преимущества более длительного курса лечения. Среди пациенток, получавших инозин пранобекс 28 дней, число случаев, требующих дополнительного лечения поражений шейки матки, оказалось в 3 раза меньше, чем среди больных, применявших более короткую схему приема препарата, и в 7 раз меньше, чем в контрольной группе.

\section{Терапия пачиентов с рецидивирующими} остроконечными кондиломами представляет для врача наиболее сложную задачу, поскольку в подобных случаях неоднократное применение деструктивных методов лечения не дает положительной динамики. Даже после многократных курсов лечения рецидивирование прекращается лишь у $40 \%$ больных

Данные из 15 источников, в которых описаны 2369 случаев применения инозина пранобекса в качестве монотерапии, 3369 - в комбинации с другими методами в сравнении с 71 наблюдением плацебо-контроля и 575 наблюдениями за традиционным лечением, свидетельствуют об эффективности вспомогательной иммунотерапии инозином пранобексом на фоне применения традиционных методов при лечении генитальных поражений, ассоциированных с ВПЧ [20].

Однако в литературных источниках встречаются и другие алгоритмы применения инозина пранобексм, отличные от рекомендованных в инструкции.

В нашей повседневной практике при лечении папилломавирусной инфекции аногенитальной области мы применяем комбинированную схему терапии. Необходимо отметить, что после деструкции количество элементов папилломавирусной инфекции может резко

\section{Рисунок 1. Количество элементов папилломавирусной инфекции после деструкции}
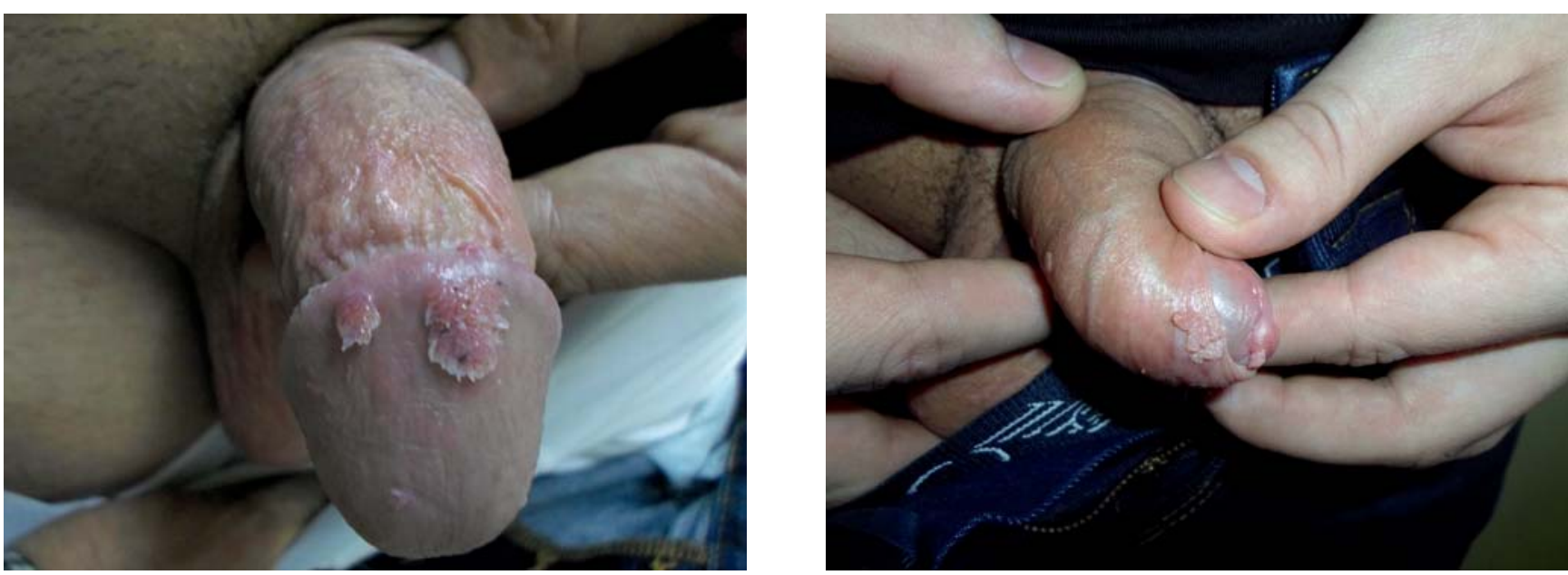


\section{Рисунок 2. Распространенная форма папилломавирусной инфекции}

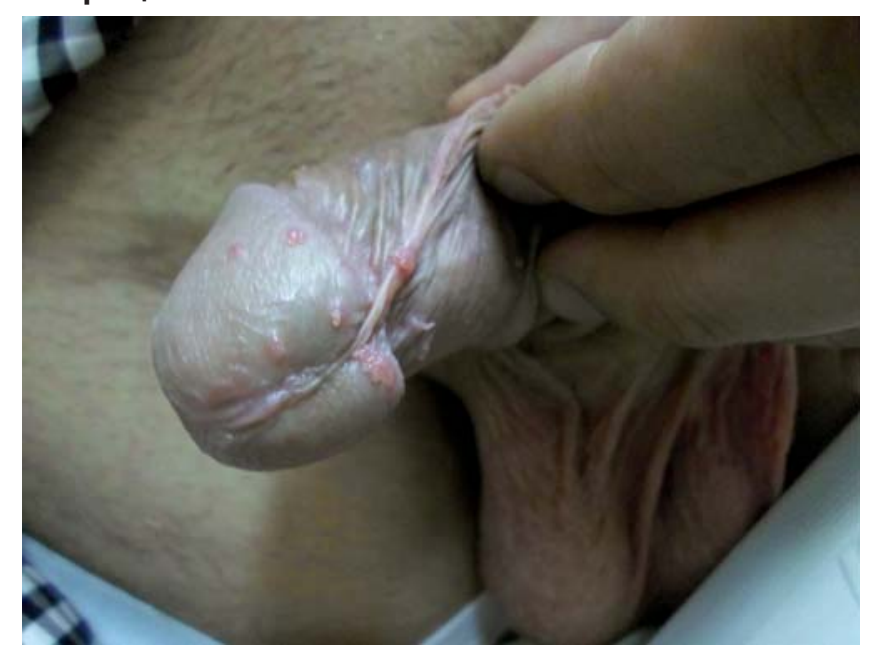

увеличиваться (рис. 1). Это одна из возможных причин назначения комплексной терапии. В нашей практике мы используем следующий алгоритм лечения рецидивирующей ПВИ: перед деструкцией за 5-7 дней назначается инозина пранобекс в дозе 500 мг 3 р/сут, после деструкции доза увеличивалась до 1 г 3 р/сут в течение 2-3 недель. Собственные наблюдения показывают, что при контрольном посещении через 3-4 месяца после окончания терапии рецидив инфекции отсутствовал. При распространенных формах ПВИ (рис. 2) необходимо для предотвращения рецидивов терапию инозином пранобексом начинать одновременно с деструкцией, доза инозина пранобекса составляет 3 г/сут в течение 21 дня.

Приведенная схема терапии применяется нами в течение нескольких лет, давая положительные результаты. Рецидив инфекции наблюдаются у пациентов в сочетание с гепатитами В и С, что говорит о необходимости обследования пациентов с множественными папилломатозными очагами на предмет сопутствующих провоцирующий заболеваний.

\section{Конфликт интересов: авторы заявляют об отсутствии} конфликта интересов в ходе написания данной статьи.

\section{ЛИТЕРАТУРА}

1. Van Krogh D, Lacey SD, Gross G, Barrasso R., Schneider A. European guidelines for anogenital warts. IPPP, 2002, 3: 29-37.

2. Александрова Ю.Н., Лыщев А.А., Сафронникова Н.Р. и др. Папилломавирусная инфекция у здоровых женщин Санкт-Петербурга. Bопр. онкол., 2000, 46(2): 175-179./ Aleksandrova YuN, Lyshchev AA, Safronnikova $\mathrm{NR}$, et al. Papillomavirus infection in healthy women in St. Petersburg. Vopr. Onkol., 2000, 46(2): 175-179.

3. Коломиец Л.А., Уразова Л.Н. Генитальная папилломавирусная инфекция и рак шейки матки. Томск: НТЛ, 2002. 100 с./ Kolomiets LA Urazova LN. Genital papillomavirus infection and cervical cancer. Tomsk: NTL, 2002.100 p.

4. Nyitray AG, Iannacone MR. The epidemiology of human papillomaviruses. Curr Probl Dermatol, 2014, 45(1): 75-91.

5. Краснов В., Кулова А., Кулова Е. и др. Реабилитация в закрытых детских учреждениях часто болеющих детей с маркерами активности герпетической инфекции. Врач, 2007, 12: 68-70./ Krasnov $\mathrm{V}$, Kulova A, Kulova E, et al. Rehabilitation in closed children's institutions of frequently ill children with herpes infection activity markers. Vrach, 2007, 12: 68-70.

6. Прилепская В.Н., Костава М.Н. Возможности терапии папилломавирусной инфекции. РМЖ 2009, 17(1): 16-19. /Prilepskaya VN, Kostava MN. Therapeutic potential of papillomavirus infection therapy. RMJ, 2009, 17 (1): 16-19.

7. Boyle P, Leon ME, Maisonneuve P, Autier P. Cancer Control In Women: Update 2003. Int J Gynaecol Obstet, 2003 Oct, 83(Suppl 1): 179-202.

8. Абрамовских О.С., Долгушина В.Ф., Телешева Л.Ф.и др. Папилломавирусная инфекция урогенитального тракта: эпидемиологические аспекты (обзор). Гинекология, 2016, 18(2): 34-39./ Abramovskikh OS, Dolgushina VF,
Telesheva LF, et al. Papillomavirus infection in the urogenital tract: epidemiological aspects (review). Ginekologiya, 2016, 18 (2): 34-39.

9. Clinical Effectiveness Group (British Association for Sexual Health and HIV). United Kingdom National guideline for the management of anogenital warts, 2007.

10. Соловьев А.М., Перламутров Ю.Н., Корсунская И.М. Сосотояние иммунной системы у больных рецидивирующими инфекциями урогенитального тракта. Иммунология, аллергология инфектология, 2013, 4: 49-56./ Soloviev AM, Perlamutrov YuN, Korsunskaya IM. Immune system status in patients with recurrent infections in the urogenital tract. Immunologiya, Allergologiya, Infektologiya, 2013, 4: 49-56.

11. Ласеев Д.И. Необходимость комбинированного лечения генитальных бородавок В сборнике: Актуальные проблемы лазерной медицины сборник научных трудов. Под редакцией Н.Н. Петрищева. Санкт-Петербург, 2016: 71-72. /Laseev DI. The need for combined treatment of genital warts. In the collected papers: Actual problems of laser medicine, a collection of research papers. Edited by Petrischev NN. St. Petersburg, 2016: 71-72.

12. Кисина В.И., Воробьев П.А. Протоколы ведения больных. Инфекции, передаваемые половым путем. М.: Ньюдиамед, 2011./Kisina VI, Vorobiev PA. Patient management protocols. Sexually transmitted infections. M: Newdiamed, 2011

13. Hersey P, Edwards A. Effect of Isoprinosine on natural killer cell activity of blood mononuclear cells in vitro and in vivo. Int J Immunopharmacol, 1984, 6: 315-320.

14. Diaz-Mitoma F, Turgonyl E, Kumar A et al. Clinical improvement in cronic fatigue syndrome is associated with enchanced natural killer cell-mediated cytotoxicity: the results of a pilot study with Isoprinosine. J Chron Fatig Syn, 2003, 11(2): 1-17.

15. Cillari E, Diell M, Lo Campo P et al. Protective effect of Isoprinosine in genetically susceptible
BALB/c mice infected with Leishmania major. Immunology, 1991, 74: 25-30.

16. Mohanty KC, Scott CS. Immunotherapy of genital warts with inosine pranobex (Imunovir): preliminary stady. Genitourin Med, 1986, 62: 352-355.

17. Баграмова Г.Э., Гуреева М.А., Хлебникова А.Н., Молочков А.В. Иммуномодулирующая терапия папилломавирусной инфекции. Клиническая дерматология и венерология, 2011, 6: 47-50./ Bagramova GE, Gureeva MA, Khlebnikova AN, Molochkov AV. Immunomodulatory therapy for papillomavirus infection. Kliniches kaya Dermatologiya i Venerologiya, 2011, 6: 47-50.

18. Кедрова А.Г., Подистов Ю.И., Кузнецов В.В., Козаченко В.Л., Никогосян С.О. Роль противовирусной терапии в комплексном лечении больных эпителиальными дисплазиями и преинвазивным раком шейки матки. Гинекология, 2005, 7: 170-173. /Kedrova AG, Podistov Yul, Kuznetsov V, Kozachenko VL, Nikogosyan SO. The role of antiviral therapy in the combination treatment of patients with epithelial dysplasia and preinvasive cervical cancer. Ginekologiya, 2005, 7: 170-173.

19. Кедрова А.Г., Леваков С.А., Челнокова Н.Н. Оптимизация медикаментозной терапии начальных повреждений эпителия шейки матки, ассоциированных с вирусом папилломы человека. Consilium Medicum, 2014, 16(6): 88-92./Kedrova AG, Levakov SA, Chelnokova NN. Optimization of drug therapy for initial damage to the cervical epithelium associated with the human papillomavirus. Consilium Medicum, 2014, 16(6): 88-92.

20. Елисеева М.Ю., Мынбаев О.А. Вспомогательная иммунотерапия ВПЧ-ассоциированных поражений слизистых оболочек и кожи урогенитальной и перианальной локализации. Гинекология, 2009, 11(5): 22-33. /Eliseeva MYu, Mynbayev OA. Adjuvant immunotherapy of $\mathrm{HPV}$-associated lesions found in the areas of the mucous membranes and skin of the urogenital and perianal region. Ginekologiya, 2009, 11 (5): 22-33. 